\title{
SOME IMMUNE FACTORS AND HORMONES IN SCIENCE DETERMINED IN FEMALE ALBINO RATS INDUCED WITH INFERTILITY AND ADMINISTERED WITH ANTHOCLIESTA VOGELI
}

\author{
Oladimeji S.O $1^{1 \star}$, Lawal O. $A^{2}$. and Steve $A^{1}$
}

${ }^{1}$ Department of Biochemistry, Faculty of Science,

Lagos State University, Nigeria

${ }^{2}$ Department of Chemistry

Faculty of Science,

Lagos State University, Nigeria

\section{Correspondence}

Oladimeji S. $\mathrm{O}^{1 *}$,

Department of Biochemistry,

Faculty of Science,

Lagos State University, Nigeria.

Email:olugbenga.oladimeji@lasu.edu.ng

\section{Funding information}

\begin{abstract}
:
Introduction: $A$. vogelii has not been scientifically proven to have the potential, for which it has been medicinally useful in treating ailments. The seed and bark are used as purgative and fertility enhancer among other claims.

Aims: Anthocleista vogelii Planch, phyto-constituents were evaluated and the plant leaf extracts effects on the hormonal and immune factors were investigated based on the claims of the traditional medicine practitioners of its usage as fertility enhancer in females.

Materials and Methods: Ethanolic extract of Anthocleista vogelii were administered orally for 14 days to female albino rats placed in different groups. First, temporary infertility was induced with Micronor (norethisterone) or Nacetylcysteine (NAC) given orally to some rats, for seven (7) days prior to other treatment. The rats were sacrificed after the completion of extract administration. The absolute counts of clusters of differentiation CD4+ and CD8+ was performed on the blood samples using the Becton Dickinson's (BD) FACS Count Automated technique. Hormonal analysis was performed on sera obtained from the experimental animals using commercial standard enzyme-linked immunosorbent assay kit.

Results: The extract was found to possess anthraquinones, terpenoids, flavonoids, saponins, alkaloids, phenols and phytosterols. The obtained results of the test group compared with control showed a statistically significant decrease $(P<0.05)$ in $C D 4+$ and $C D 8+$ counts cells, prolactin, testosterone respectively. The results showed a significant increase of estradiol and luteinizing hormone in the female rats in the control group compared to extract treated group. The result also suggests that Anthocleista vogelii may have a role in creating the environment required for enhancing pregnancy by decreasing ratio of CD4+ and CD8+.

Conclusion: The findings therefore support the claims on the traditional use of Anthocliesta vogelii in that it enhances fertility in female.

Keywords: Ethanolic extract, Anthocleista vogelii, WBC, female fertility, CD4+ and CD8+, oestradiol, prolactin
\end{abstract}

This is an open access article under the terms of the Creative Commons Attribution License, which permits use, distribution and reproduction in any medium, provided the original work is properly cited.

(c) 2018 The Authors. Journal of Research and Reviews in Science-JRRS, A Publication of Lagos State University 


\section{INTRODUCTION}

Sexual function is an important component of quality of life and subjective well-being in humans. Sexual problems are widespread and adversely affect mood, well-being, and interpersonal functioning [1] The main sexual problems are related to sexual desire and male erectile dysfunction. Successful treatment of sexual dysfunction may improve not only sexual relationships, but also the overall quality of life, [2].

De Smet, [3], reported that the plant Anthocleista vogelii belongs to the family Loganiaceous. The tree is 20 to 30 $\mathrm{ft}$ high, and 3 to $4 \mathrm{ft}$ in girth with comparatively few widely spreading crooked branches and stout gnarled branch let's bearing the leaves in tuft at the ends. Bark is grey to pale brown, smooth to slightly fissure longitudinally, cream to pale brown, sometimes streaked with red. The leaves and stem-bark are used for treating swellings in the body (anti-inflammatory). The root-bark and leaves are used in local medicine [45]. The root decoction is drunk in Sierra Leone for chest pain, the wood-ash is used for soap making, while the wood is used as a quiver for arrows and packing cases. Some traditional healers have claimed that some medicinal plants in Nigeria like Anthocleista vogelii could be used to treat obesity in Nigeria, [5]. A. vogelii has not been scientifically proven to have anti-obesity potential, they have been reported to be medicinally useful in other ailments, [6]. The seed and bark are used as purgative and antidote for snake bite. The bark and root are used in the healing of dropsy, swellings, oedema, gout and venereal diseases. The leaf-bud serves as antidotes for venomous stings, bites, $[4,5,7]$ demonstrates the anti-plasmodia effects of petroleum ether extract of leaf of $A$. vogelii.

There are different metabolic pathways for estradiol metabolism in women depending on body weight. Slender women metabolize estradiol to 2hydroxyestrone- and antiestrogens. Obese women metabolize estradiol to estriol, a weak estrogen. The rate of metabolism changes seems to correlate with the body fat total body mass. Thus, slender women progressively "turn down" the reproductive cycle until it is "turned off" when the condition of anorexia nervosa (defined as less than $85 \%$ of predicted ideal body weight for height) is reached.

The present investigation was designed to evaluate the claims of the traditional medicine practitioners on the usage of Anthocleista vogelii Planch; as fertility enhancer in females, to study the beneficiary effect of the extract on the liver, and to check for other biochemical parameters of the plant using female albino rats as model, [8].

\section{MATERIAL AND METHODS}

2.1 Plant Material: Leaves of Anthocleista vogelii were collected in large quantities from the forests of Imoshe, Ogun State, Nigeria. These was taken for authentication at the Taxonomy Unit, Department of Botany, University of Lagos and obtained the voucher specimen (No: LUH/5652) The leaves were deposited in the herbarium of the Institute and also deposited at the Department of Biochemistry, Lagos State University for future reference.

2.2. Preparation of The Ethanolic Extract: The leaves of the plant were washed well with water, dried under shade for 14 days and powdered to fine grade using electric blender. A batch of $200 \mathrm{~g}$ of powdered material was subjected to cold maceration extraction in 50\% $(\mathrm{v} / \mathrm{v})$ of $1 \mathrm{~L}$ of ethanol with intermittent shaking at room temperature for 3 days (72 hours). The extract was then filtered, and yielded $620 \mathrm{ml}$ of crude which was lyophilized to $15 \mathrm{~g}$ of the ethanolic extract corresponding to an extraction yield of $7.5 \%$ and stored in the freezer. This extract was re-dissolved in distilled water when ready for administration.

2.3.1 Phytochemical Studies: Phytochemical screening of the extract was carried out using standard procedures to identify the constituents [9] in modified methods of Somkuwar and Kamble [10].

2.3.2. Toxicity Test: Acute toxicity test was performed according to [11]. Nine (9) rats were randomly selected (three per group) and starved overnight. Extract doses of 150,250 and $400 \mathrm{mg} / \mathrm{kilogram}$ body weight were administered to each animal group respectively. The animals were kept under the same natural condition and observed for toxicity signs and mortality for 72 hours. All dosage administered were found to be non-lethal as earlier determined as being safe doses as reported [11].

2.4 Animal Study: Sixty (60) healthy female Wister albino rats of average weight of $100 \mathrm{~g}$ were procured from an inbred stock at University of Ibadan, Oyo State, Nigeria. The animals were acclimatized with the laboratory environment for 3 weeks. The experiment was approved by the Ethical committee of the College of Medicine following the edition of the Guide for care and use of Laboratory Animals (National Research Council, 1996)

2.4.1 Animal Treatment: Forty-two (42) female Wister albino rats with an average weight of $120 \mathrm{~g}$ were randomly selected and divided into seven (7) groups with six (6) animals per group. The infertile group was obtained using $\mathrm{N}$-acetylcysteine (NAC) or Micronor (Norethisterone, a proven female contraceptive) used to induce reversible infertility in this rat groups. The treatments for each group were as follows:

Group I: Rats were administered with $1 \mathrm{ml}$ of distilled water once a day for 21 days. 
Group II: Rats were administered with micronor (norethisterone) at a dose of $20 \mu \mathrm{g} / \mathrm{kg}$ body weight once a day in a volume of $1 \mathrm{ml}$ for 7 days.

Group III: Rats received NAC (N-Acetylcysteine) at a dose of $1000 \mathrm{mg} / \mathrm{kg}$ body weight once a day in a volume of $0.74 \mathrm{ml}$ for 7 days.

Group IV: Anthocleista vogelii extract was administered to rats at a dose of $100 \mathrm{mg} / \mathrm{kg}$ body weight once a day in a volume of $0.25 \mathrm{ml}$ for 21 days.

Group V: Rats were administered with micronor (norethisterone) at a dose of $20 \mu \mathrm{g} / \mathrm{kg}$ body weight once a day in a volume of $1 \mathrm{ml}$ for 7 days and thereafter administered with Anthocleista vogelii extract at a dose of $100 \mathrm{mg} / \mathrm{kg}$ body weight in a volume of $0.25 \mathrm{ml}$ for 14 days.

Group VI: Rats were administered with micronor (norethisterone) at a dose of $20 \mu \mathrm{g} / \mathrm{kg}$ body weight once a day in a volume of $1 \mathrm{ml}$ for 7 days and thereafter administered with Anthocleista vogelii extract at a dose of $200 \mathrm{mg} / \mathrm{kg}$ body weight in a volume of $0.5 \mathrm{ml}$ for 14 days.

Group VII: Rats received NAC (N-Acetylcysteine) at a dose of $1000 \mathrm{mg} / \mathrm{kg}$ body weight once a day in a volume of $0.74 \mathrm{ml}$ for 7 days, and thereafter administered with Anthocleista vogelii extract at a dose of $100 \mathrm{mg} / \mathrm{kg}$ body weight in a volume of $0.25 \mathrm{ml}$ for 14 days.

All administrations were performed orally with the aid of cannula. On completion of administration, the rats in the different groups were anaesthetized with diethyl ether via inhalation. Blood samples were collected from the animals through cardiac puncture and collected into properly labelled $\mathrm{K}_{3}$ EDTA vacutainer tubes and plain tubes for analysis.

2.5 Immunological Biomarkers Analysis: CD4+ and CD8+ analysis was performed using the BD FACS Count Automated CD4+/CD8+ absolute count technique. A successful control run was necessary before running the test samples to ensure reliable results.

2.6 Hormonal Assay: Estradiol, prolactin, testosterone and luteinising hormone analysis were performed on the serum samples obtained from the animals using commercial standard Enzyme - Linked Immunosorbent Assay (ELISA) kit.

\subsection{VITAMIN E ASSAY}

The vitamin $\mathrm{E}$ analysis was performed using HPLC

\subsection{Statistical Analysis}

Data were analyzed using One Way Analysis of Variance (ANOVA, SPSS Version 20) and expressed as mean \pm Standard Error Mean (SEM). Differences between groups were regarded significant at $\mathrm{P}_{+} 0.05$ and post-hoc tests were then performed using the Tukey's test.

\section{RESULTS}

\subsection{PHYTOCHEMICAL CONSTITUENT:}

The phytochemical studies revealed the presence of anthraquinones, saponins, flavonoids, alkaloids flavonoids, alkaloids, terpenoids, phenols and Phytosterols.

Table 1: Phytochemical investigation of the leaf of Anthocleista vogelii

\begin{tabular}{|l|c|}
\hline \multicolumn{1}{|c|}{ TEST } & INFERENCE \\
\hline Reducing Sugar & -ve \\
\hline Terpenoids & $+\mathrm{ve}$ \\
\hline Flavonoids & $+\mathrm{ve}$ \\
\hline Saponins & $+\mathrm{ve}$ \\
\hline Tannins & $-\mathrm{ve}$ \\
\hline Alkanoids & $-\mathrm{ve}$ \\
\hline Cardiac glycosides & $-\mathrm{ve}$ \\
\hline Protein/Amino Acids & $-\mathrm{ve}$ \\
\hline Phenols & $+\mathrm{ve}$ \\
\hline Phytosterols & $+\mathrm{ve}$ \\
\hline
\end{tabular}

-ve: absent

+ve: present

\subsection{EFFECTS ON SEX HORMONE}

The Testosterone Prolactin leutinizing conc estradiol concentration of the blood obtained from each animal group was analysed and the values obtained are represented graphically below in fig 1,2,3 and 4 respectively. 


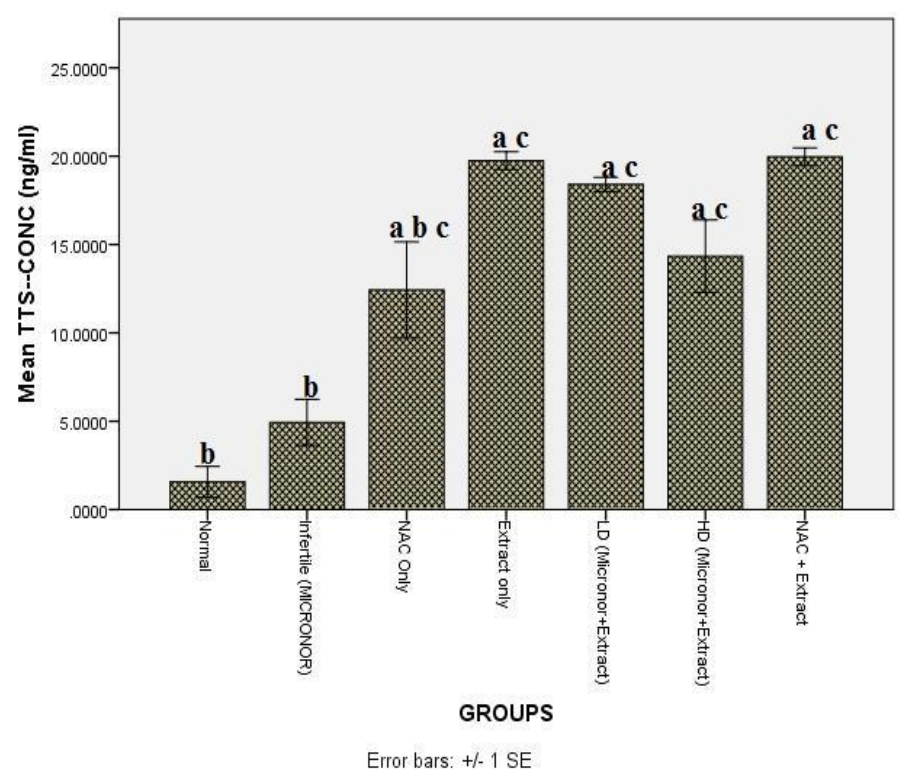

Figure 1: Graphical representation of Testosterone level count.

a represents significant value compared to normal group (i.e. distilled water),

b represents significant value compared to extract group,

c represents significant value compared to infertile (micronor) $(\mathrm{P}<0.05$, ANOVA post hoc Tukey HSD test).

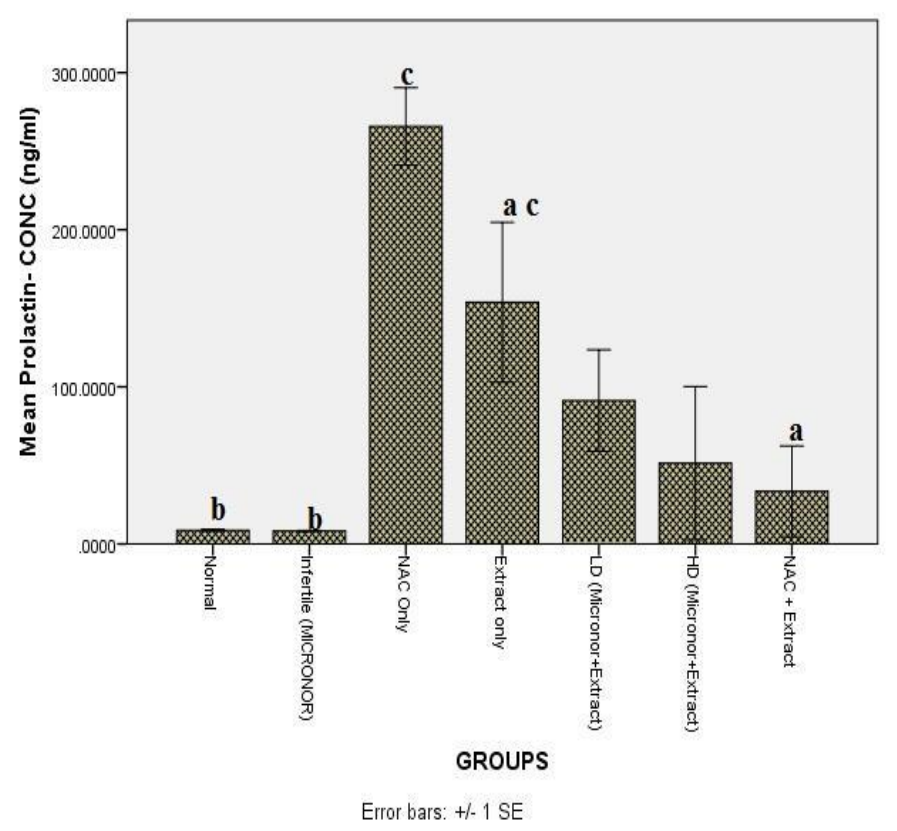

Figure 2: Graphical representation of Prolactin count.

a represents significant value compared to Normal group (i.e. distilled water),

b represents significant value compared to extract group,

c represents significant value compared to infertile (micronor) $(\mathrm{P}<0.05$, ANOVA post hoc Tukey HSD test)

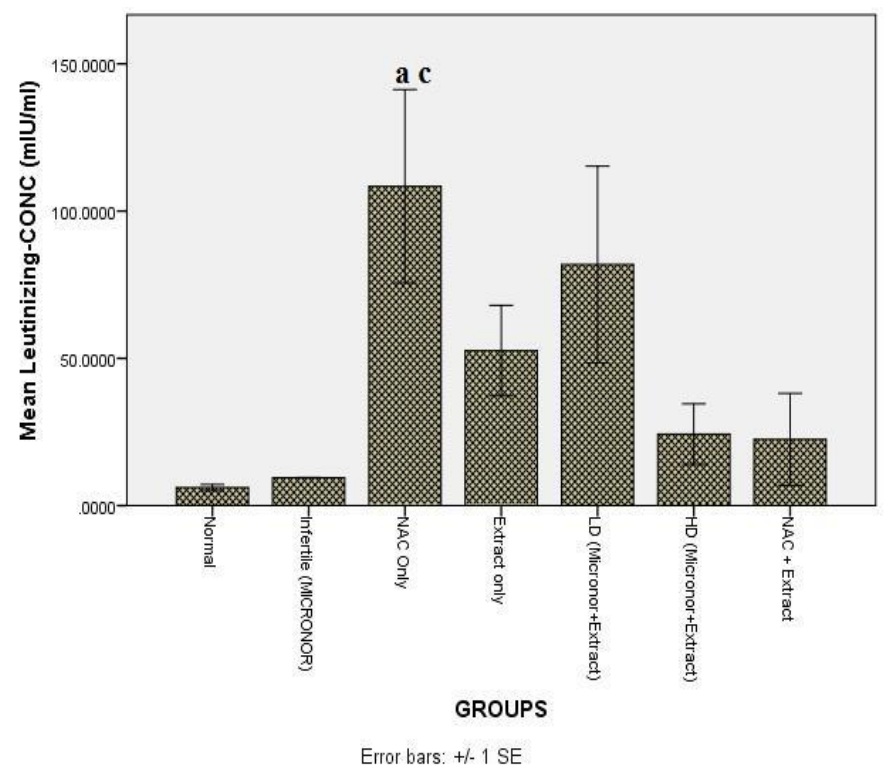

Fig.3: Graphical representation of leutinizing count

a represents significant value compared to normal group (i.e. distilled water),

c represents significant value compared to infertile (micronor) $(\mathrm{P}<0.05$, ANOVA post hoc Tukey HSD test).

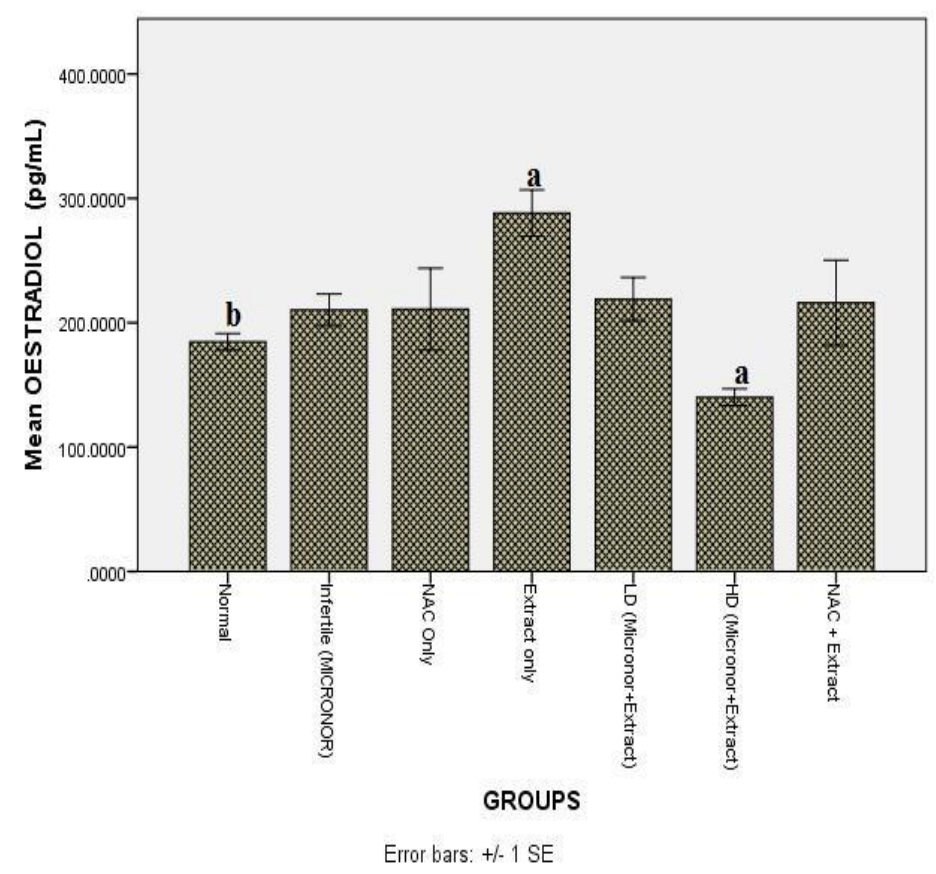

Figure 4: Graphical representation of estradiol concentration

a represents significant value compared to Normal group (i.e. Distilled Water),

${ }^{b}$ represents significant value compared to extract group $(P<0.05$, ANOVA post hoc Tukey HSD test) 


\subsection{EFFECTS ON IMMUNOLOGICAL BIOMARKERS}

The CD4 and CD8 cells concentration as counted from all the animal groups are presented in Figure 5 and Figure 6 below for CD8 and CD4 cells respectively:

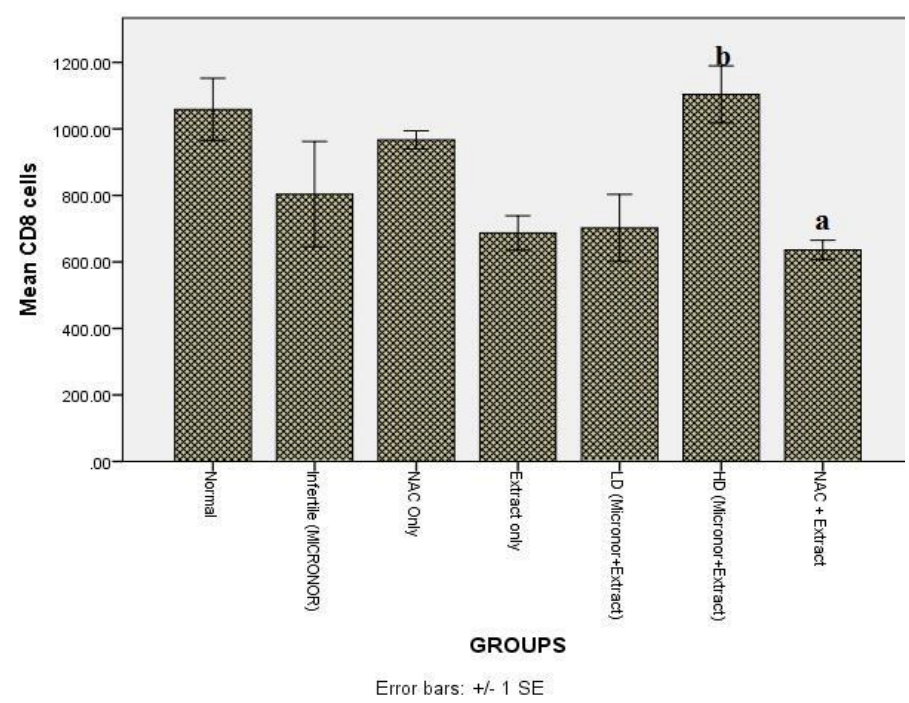

Figure 5: Graphical representation of CD8+ cells count.

a represents significant value compared to Normal group (i.e. distilled water),

b represents significant value compared to extract group $(P<0.05$, ANOVA post hoc Tukey HSD test).

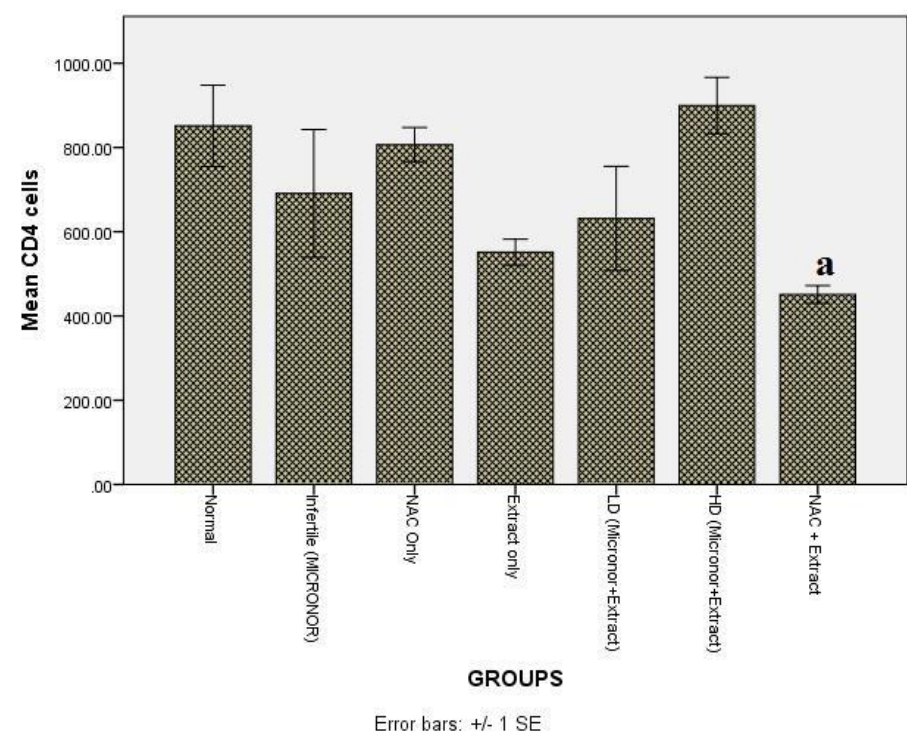

\section{Figure 6: Graphical representation of CD4+} cells count.

represents significant value compared to control group (i.e. distilled water) $(P<0.05$, ANOVA post hoc Tukey HSD test).

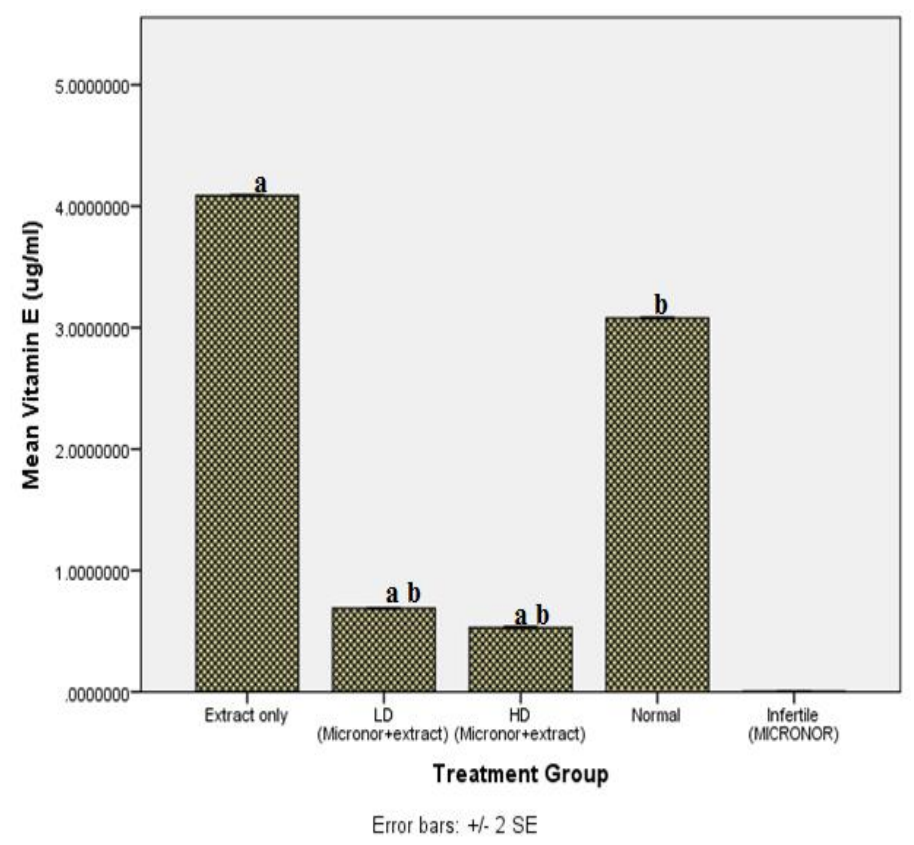

Figure 7: Graphical representation of vitamin

E.

a represents significant value compared to Normal group (i.e. distilled water),

b represents significant value compared to extract group,

c represents significant value compared to infertile (micronor) $(\mathrm{P}<0.05$, ANOVA post hoc Tukey HSD test).

Table 1 showed that the ethanolic extract of Anthocleista vogelii is composed of anthraquinones, terpenoids, flavonoids saponins, alkaloids, phenols and phytosterols which suggest its potentials to effect the observable efficacy acclaimed by African traditional medicine practitioners. It is suggestive that the ethanolic extract of Anthocleista vogelii used in this present study which contains saponins reduced the fat accumulation, thereby increasing chances of fertility by correcting their body weight disorder.

The testosterone Irolactin luteinizing and estradiol concentration of the blood obtained from each animal group were analysed and the values obtained are represented graphically in figures $1,2,3$ and 4 respectively

The result show that ethanolic plant extracts is beneficial to the liver, thus increasing the expression of oestrogen receptor which is critical for maintaining fertility. Reports had earlier shown that oestrogen receptors in the liver are critical for maintaining fertility, and those receptors are under the control of dietary amino acids; the building block of proteins. The idea that diet may have impact on fertility is not totally new of course, but explains how diet, and especially a diet poor in protein can have a direct influence.

The CD4 and CD8 cells counts obtained from all the animal groups are presented in Figure 5 and Figure 6 
respectively. These immunological markers level showed that extract treated group had a lower CD4 and CD8 counts, and even significantly decreased count in the NAC and extract treated group. This is indicative of lower immunological stress in these groups.

Figure 7 results represent the concentration of vitamin $E$ in the groups. The concentration of vitamin $E$ as nonenzymatic anti- oxidants was significantly lower in the induced infertile groups compared to the normal and the extract treated groups.

The Anthocleista vogelii extract significantly decreased the total fat of the group of animals administered with extract which suggest that the body weight may have been restored to normal establish limit necessary for fertility. Some of the chemical constituents, such as saponins, flavonoids and some triterpenoids have been reported for their anti -obesity effect in various plants [8].

Saponins as natural products are also involved in complexation with cholesterol to form pores in cell membrane bilayers [12], as such may be used as anticholesterol agents or cholesterol lowering agent. Thus, it is suggestive that the ethanolic extract of anthocliesta vogelii used in this present study which contains saponins reduced the fat accumulation in the albino rat administered with Anthocliesta vogelii ethanolic extract, [6]. In the albino rat administered with Anthocleista vogelii ethanolic extract in which the sex steroid hormone -testosterone (the principal female hormone) are lipid soluble i.e.; they dissolve in fat but not in water. Thus, these hormones accumulate in body fat. Once body fat stores are saturated with sex steroid hormones, they reach equilibrium with the blood.

In addition to the storage capacity of the body fat of sex steroid hormones (fat cells) convert the androstenedione, to the weak female hormone, estrone. Estrone though not as potent as estradiol has metabolic effects on the hypothalamus- pituitary axis of the brain (the area of the brain that regulates testicular and ovarian function) to alter reproductive function. These complex interactions have a net effect of impairing reproductive function. These effects of body weight on female reproductive function are well established, [1]. In addition to the stored hormones in body fat; the gonads secrete testosterone and estradiol to maintain the levels necessary to sustain reproductive function, [1].

Miscarriage and pregnancy have been associated with a variety of biological phenomena including increased oxidative stress, angiogenesis and apoptosis. In a successful pregnancy however, changes occur within the peripheral blood that offers protection from the negative effects of free radicals [2].

On the other hand, obese women progressively increase their alternate estrogens; estrone and estrioluntil ovulation ceases and they become infertile. It is ironic that thin people and obese women develop irregular reproductive cycles, but by entirely different mechanisms. Thin women are estrogen deficient whereas obese women have excess of estrogen but do not cycle on a regular basis, [2].

\section{CONCLUSION:}

This study results suggests strengthening the claims of the traditional practitioner on the use of Anthocleista vogelii to boost reproductive function in female fertility, although the study has not been able to identify the basic principle responsible for this effect.

Previous report had shown that liver expressed oestrogen receptors, and that those receptors played some role in metabolism. It was suggested that thus, there is a connection between amino acids, oestrogen receptors signalling in the liver and reproductive functions may have clinical implications

The results also suggest that the extract may have a role in creating the environment required for successful pregnancy by decreasing ratio of CD4+ and CD8+ linked Th1 and Th2 cytokines production and increasing monocytes and granulocytes activation; and that the plant may also have a role in treatment of menstrual cycle disorder. The plant may be administered to induce oestrogen production.

\section{ACKNOWLEDGEMENTS}

We acknowledged staff Biochemistry Department LASU who provided assistance in manuscript preparation, and interpretation of data; in the writing of the manuscript.

\section{COMPETING INTERESTS}

Authors declare no competing interests exist.".

\section{AUTHORS' CONTRIBUTIONS}

All authors read and approved the final manuscript."

\section{ETHICAL APPROVAL}

All authors hereby declare that all experiments have been examined and approved by the appropriate ethics committee and have therefore been performed in accordance with the ethical standards laid down in the 1964 Declaration of Helsinki. 


\section{REFERENCES}

1. Lentz, M, Gretchen, Lobo, A., Rogerio, Gershenson, M, David, And L, Vern. (2013). Comprehensive gynecology. Hum. Reprod, 45 252-256.

2. Jackson L.W, Schisterman E.F, Dey Rao R, Browne R, And Armstrong D . (2014). Oxidative stress and endometriosis. . Hum Reprod 2005;20:2014-20.

3. De Smet. P.AG.M,.(1991) Is there any danger in using traditional remedies. Journal of Ethnopharmacology

4. Deepak, Kumar Semwal, Ruchi Badoni Semwal, Ilze Vermaak, And Viljoen, Alvaro. (2014). From arrow poison to herbal medicine The ethnobotanical, phytochemical and pharmacological significance of Cissampelos (Menispermaceae). Journal of Ethnopharmacology, 155 1011-1028.

5. Burkill HM (1985). The useful plants of West Tropical Africa. 2nd edn. Vol. 2. The White friars Press limited, Great Britain. pp. 352-364.

6. Sunni, L Mumford, Richard W Browne, Karen C Schliep, Jonathan Schmelzer, Torie C Plowden, Schisterman, And Enrique F. (2016). Serum Antioxidants Are Associated with Serum Reproductive Hormones and Ovulation among Healthy Women. J Assist Reprod Genet ; 8, 783-804.
7. Alaribe CSA, Coker HAB, Shode FO, Ayoola G, Adesegun SA, Barimo J, Anyim El, Anyakora C (2012). Antiplasmodial and Phytochemical Investigations of Leaf Extract of Anthocleista vogelii (Planch). J. Nat. Prod. 5: 60-67.

8. Thomas, R., Tripathi, R., Kamatm S.D. and Kamat, D.V.. 2012. Comparative study of phenolics and antioxidant activity of phytochemicals of $T$. chebula extracted using microwave and ultrasonication. Int. J. Pharm. Sci. Res. 3(1): 194-197.

9. Trease GE. Evans WC (1989). Trease and Evans' Pharmacognosy 13th Edition. published by Bailliere Tindall, pp. 282-396. Available: http://www.globalizationandhealth.com/content /1/1/14.

10. Somkuwar, D. O. and Kamble, V. A. (2013): Phytochemical screening of ethanolic extracts of stem, leaves, flowers and seed kernels of Magnifera indica L. International Journal of Pharma \& Bio Sciences. 4(2): 383 - 389.

11. Ekeanyanwu, R. C, Udeme, A. A, Onuigbo, A. $O$, And F, Etienajirhevwe O. (2012). Antidiabetic effect of ethanol leaf extract of Cissampelos owariensis (lungwort) on alloxan induced diabetic rats. African Journal of Biotechnology Vol. 11(25), pp. 6758-6762.

12. Francis C, George G, Zohar K, Harinder PS, Makhar LM, Klaus B (2002). The biological action of saponins in animal system: a review. Br. J. Nutr. 88(6):587-605I.. 